\title{
Stillbirth classification in population-based data and role of fetal growth restriction: the example of RECODE
}

Anne Ego ${ }^{1,2,4^{*}}$, Jennifer Zeitlin², Pierre Batailler ${ }^{1}$, Séverine Cornec ${ }^{1}$, Anne Fondeur ${ }^{1}$, Marion Baran-Marszak Pierre-Simon Jouk', Thierry Debillon ${ }^{1}$ and Christine Cans ${ }^{1,3}$

\begin{abstract}
Background: Stillbirth classifications use various strategies to synthesise information associated with fetal demise with the aim of identifying key causes for the death. RECODE is a hierarchical classification of death-related conditions, which grants a major place to fetal growth restriction (FGR). Our objective was to explore how placement of FGR in the hierarchy affected results from the classification.

Methods: In the Rhône-Alpes region, all stillbirths were recorded in a local registry from 2000 to 2010 in three districts ( $N$ =969). Small for gestational age (SGA) was defined as a birthweight below the $10^{\text {th }}$ percentile. We applied RECODE and then modified the hierarchy, including FGR as the penultimate category (RECODE-R).

Results: $49.0 \%$ of stillbirths were SGA. From RECODE to RECODE-R, stillbirths attributable to FGR decreased from 38\% to $14 \%$, in favour of other related conditions. Nearly half of SGA stillbirths (49\%) were reclassified. There was a non-significant tendency toward moderate SGA, singletons and full-term stillbirths to older mothers being reclassified.

Conclusions: The position of FGR in hierarchical stillbirth classification has a major impact on the first condition associated with stillbirth. RECODE-R calls less attention to monitoring SGA fetuses but illustrates the diversity of death-related conditions for small fetuses.
\end{abstract}

Keywords: Stillbirths, Classification, Cause of death, Associated conditions, Small for gestational age, Fetal growth

\section{Background}

Classifications of perinatal deaths are needed for health care policy, surveillance, international comparisons, clinical services, and research. There is a wide variety of these classifications in the literature, reflecting differences in criteria and available information for recording stillbirths and in existing health information systems over time and between countries [1,2]. Some of them include categories best suited for epidemiology and health care planning purposes, including risk factors such as small for gestational age (SGA) or twin pregnancy, while others aspire to provide information on the cause of

\footnotetext{
* Correspondence: aego@chu-grenoble.fr

'The RHEOP (Registre des Handicaps de l'Enfant et Observatoire Périnatal Isère, Savoie et Haute-Savoie), Grenoble, France

${ }^{2}$ INSERM, UMR S953, Epidemiological Research on Perinatal Health and Women's and Children's Health, Paris, France

Full list of author information is available at the end of the article
}

death, focusing on specific clinical groups relevant to biomedical research questions [3].

After a substantial decrease of the stillbirth rate, by two-thirds from 1950 to 1975, related to prevention and treatment of infection and improved obstetric care, this decline has slowed or halted in high-income countries during the last few decades [4]. Authors of the Lancet's Stillbirths Series in 2011 suggested that classification should be the first research priority in epidemiological measurement, and underline the need for "the optimum investigation protocol for stillbirth to identify causes and relevant conditions in terms of yield, utility and costs" in high-income countries. Most classifications consistently report up to two-thirds of fetal deaths as being unexplained or unknown [1]. Several factors contribute to increasing the number of unexplained or unknown cases, such as the design of the system itself or the lack of postmortem investigation. 
The classification called RECODE (RElevant COndition at DEath) is intended to be used in a strictly hierarchical manner and designed to organize information on the clinical conditions associated with the death rather than why the death occurred [5]. This makes it possible to avoid a case-by-case analysis of the circumstances leading to the death and to apply the classification retrospectively to existing databases. Other strengths of this classification are that is has a clear hierarchical structure, is based on ICD codes, and enables $85 \%$ of stillbirth cases to be assigned a relevant condition. In 2009, RECODE was ranked third in the International Stillbirth Alliance out of six contemporary systems designed specifically for stillbirths: Amended Aberdeeen, Extended Wigglesworth, PSANZ-PDC, CODAC and Tulip [3]. They concluded that the best classifications collect all relevant information, use a hierarchical approach as a guide, but rely on expert opinions in order to preserve the relative importance of the narrative [6-8].

The RECODE classification grants significant importance to fetal growth restriction (FGR) relative to other clinical conditions. This is concordant with previous analyses of the pathophysiology of conditions underlying stillbirths [2]. This choice is also supported by the potential preventability of stillbirths associated with FGR [9]. However, the placement of FGR in the RECODE classification may override important information on other related conditions. For instance, when autopsy and placental examinations exist they provide information on placental pathology, which is a frequent antecedent of both FGR and stillbirth [10]. These anomalies are also part of a large group of clinical scenarios associated with maternal vascular disease and FGR [11,12].

The aim of this study was to test how the hierarchical ranking of FGR affected the classification of stillbirths in a large population-based registry in the Rhône-Alpes region from 2000 to 2010. We compared the RECODE classification with an alternative hierarchy, labelled RECODE-R in which FGR was only retained in the absence of other clinical conditions.

\section{Method}

\section{Study design}

The RHEOP (Registry of childhood handicaps and perinatal observatory) was created in 1988 in the Isère district in the Rhône-Alpes region of France. The area covered by the registry was enlarged to include two contiguous districts in 2005 (Savoie and Haute-Savoie). This registry includes all cases of childhood disability as well as all stillbirths to residents in these districts [13]. Its objective is to monitor the trends in stillbirth, to identify causes of death, and to improve the interpretation of trends in childhood disability by taking into consideration trends in stillbirths and pregnancy terminations. The three participating districts constitute a population-based sample of 30000 births per year. The RHEOP registry uses the WHO definition of a stillbirth, i.e., "the birth of a baby with a birth weight of $500 \mathrm{~g}$ or 22 or more completed weeks of gestation who died before or during labor and birth" [14].

The RHEOP stillbirth register was approved by the French data protection authority Commission on Information Technology and Liberties (CNIL) (approval number 997086). This approval covers secondary analyses of these data.

Stillbirths are identified in maternity hospitals by several investigators, who are trained nurses, midwives or physicians. They complete a standardized form based on the medical record for each case, which contains maternal age, occupation and profession, medical history, complications of pregnancy, findings of prenatal screening, elective terminations of pregnancy, delivery mod, time of death, gestational age and birth weight, and placental examination or fetal autopsy when this exists. Fetal autopsy and/or placental examination were performed for $77.4 \%$ of the study sample. Secondarily, the investigators encode the information into ICD codes $\left(10^{\text {th }}\right.$ edition) up to two maternal and six fetal diagnoses.

For the purposes of the study, we excluded all elective pregnancy terminations. The database consisted of 1030 stillbirths weighing $500 \mathrm{~g}$ or more, or 22 or more completed weeks of gestation, distributed over 11 years from 2000 to 2010, corresponding to a stillbirth rate of 3.8 per 1000 total births.

\section{Definition of SGA}

Because maternal weight, height and parity were not recorded, we were not able to define SGA by customized birth weight standards [15]. We used a previous French multicenter study intended to develop and evaluate customized birth weight curves suitable for France [16]. We defined SGA using the $10^{\text {th }}$ centile of sex differentiate norms according to Hadlock's formula for fetal growth curves, fitted to birth weights registered in the French Perinatal Survey in 1998 [17,18]. Severe SGA babies (below the $3^{\text {rd }}$ percentile) were distinguished from moderate SGA babies $\left(3^{\text {rd }}-10^{\text {th }}\right.$ percentile). This information encoded in ICD code was added retrospectively whether or not this diagnosis was mentioned in the patient's case notes.

We used the term "SGA" to refer to fetuses with a birthweight under the $10^{\text {th }}$ percentile, whereas the term "FGR" refers to the condition retained from the classification.

\section{Classification program}

The RECODE classification contains 9 main categories from A (fetal conditions) to I (unclassified), each of them divided into several subgroups, totalling 37 subcategories 
[5]. These categories are anatomically ranged from fetal diseases to external maternal injury, and contained a variety of fetal and maternal diseases called conditions. Among the clinical conditions provided for each case, the primary condition is the first on the hierarchical list that is applicable to a case. A secondary condition can be defined on this list. FGR is the last subcategory in category A corresponding to fetal conditions. Unexplained cases are divided into two subcategories in RECODE: either cases with irrelevant conditions despite information or cases lacking available information.

For registry data to be used retrospectively, each clinical condition converted to the ICD code had to be assigned a subcategory. We sought the help of RECODE's authors for matching each distinct maternal or fetal ICD code in the database with a subcategory. Forty-eight per cent of the ICDs codes in our database (174/360) had already been mapped. Among the blocks related to the perinatal period "O" (pregnancy, childbirth and the puerperium), "P" (certain conditions originating in the perinatal period), and to congenital malformations, deformations and chromosomal abnormalities " $Q$ ", this rate was $64 \%$. The remaining codes were more often codes assigned to maternal disease or conditions irrelevant to the death, or to different extensions of codes previously mapped.

The next step consisted in repeating a merging procedure between the main database and two additional files containing maternal and fetal ICD codes and their associated subcategory, for each of the eight potential diagnoses per case. The RECODE hierarchical rules were applied twice to select the first and the second relevant conditions. Lastly, the alternative hierarchy RECODE-R was tested. RECODE-R consisted in moving FGR down just above the unexplained cases, so that growth failure was retained only in the absence of all other conditions.

\section{Analysis}

Stillbirths with missing data on gestational age, birth weight or sex were excluded. We described our population study and the results of the classification in the whole sample and for SGA stillbirths. Cases, for whom the first condition moved from RECODE to RECODE-R, were designated as "reclassified." Reclassified SGA stillbirths were compared to SGA cases that were not reclassified.

Statistical analysis was performed using Intercooled STATA (Version 10, Stata Corporation, College Station, TX, USA); $X^{2}$ tests were used for qualitative variables and Student's test for continuous variables. $P$-values less than 0.05 were considered statistically significant.

\section{Results}

During the study period, 1030 stillbirths were recorded, and $61(5.9 \%)$ were excluded due to missing data on gestational age $(n=1)$, birth weight $(n=42)$, sex $(n=24)$, gestational age below 22 weeks $(n=1)$ or gender ambiguity $(n=5)$. They were more often preterm fetal deaths $(88.3 \%$, $p=0.001)$ and multiple pregnancies $(26.3 \%, p=0.001)$. The final sample contained 969 stillbirths.

Table 1 presents the main characteristics of the sample. Antepartum and intrapartum deaths represented respectively, 81.6 and $15.0 \%$ of the cases, and $26.8 \%$ of the cohort were full-term stillbirths. Maternal age was below 25 and above 35 years old in 17.8 and $24.7 \%$, respectively. Twelve per cent were twin pregnancies. The rate of SGA stillbirths was $49.0 \%$, and most of them had a birth weight below the $3^{\text {rd }}$ centile (39.2\%).

Table 2 shows the distribution of RECODE and RECODE-R categories and subcategories for all stillbirths and for all SGA stillbirths (the group non-SGA stillbirths only is not displayed in the table). Category A was composed of lethal congenital anomalies (A1), infection (A2), non-immune hydrops (A3), iso-immunization (A4), fetomaternal haemorrhage (A5), twin-twin transfusion (A6) and FGR (A7), and accounted for $58.7 \%$ of conditions retained in the total sample with RECODE. Its largest subcategory was A7 FGR (38.2\%). The next three main

Table 1 Characteristics of stillbirths in the RHEOP registry, 2000-2010

\begin{tabular}{|c|c|c|c|}
\hline \multirow[t]{2}{*}{ Characteristics } & & \multicolumn{2}{|c|}{ Total $(n=969$} \\
\hline & & $n$ & $\%$ \\
\hline & & \multicolumn{2}{|c|}{ mean $\pm S D$} \\
\hline \multirow[t]{5}{*}{ Maternal age (years) } & $<25$ & 172 & 17.8 \\
\hline & $25-29$ & 276 & 28.5 \\
\hline & $30-34$ & 278 & 28.7 \\
\hline & $\geq 35$ & 239 & 24.7 \\
\hline & Missing & 4 & 0.4 \\
\hline Gestational age (completed weeks) & & \multicolumn{2}{|c|}{$30.7 \pm 6.4$} \\
\hline \multirow[t]{3}{*}{ Gestational age (completed weeks) } & $22-28$ & 406 & 41.9 \\
\hline & $29-36$ & 303 & 31.3 \\
\hline & $37+$ & 260 & 26.8 \\
\hline Birth weight (grams) & & \multicolumn{2}{|c|}{$1552 \pm 1114$} \\
\hline \multirow[t]{3}{*}{ Birth weight percentile } & $\geq 10$ th & 494 & 51.0 \\
\hline & 3rd-10th & 95 & 9.8 \\
\hline & $<3 r d$ & 380 & 39.2 \\
\hline \multirow[t]{2}{*}{ Gender } & Male & 516 & 53.3 \\
\hline & Female & 453 & 46.7 \\
\hline \multirow[t]{3}{*}{ Multiple birth } & Yes & 115 & 11.9 \\
\hline & No & 823 & 84.9 \\
\hline & Missing & 31 & 3.2 \\
\hline \multirow[t]{3}{*}{ Time of death } & Intrapartum & 145 & 15.0 \\
\hline & Antepartum & 791 & 81.6 \\
\hline & Missing & 33 & 3.4 \\
\hline
\end{tabular}


Table 2 RECODE and RECODE-R classifications among the whole sample and SGA stillbirths

\begin{tabular}{|c|c|c|c|c|c|c|c|c|}
\hline \multirow{3}{*}{$\begin{array}{l}\text { Primary relevant condition } \\
\text { of deatht } \\
\text { Categories and subcategories }\end{array}$} & \multicolumn{4}{|c|}{$\underline{\text { RECODE }}$} & \multicolumn{4}{|c|}{ RECODE-R } \\
\hline & \multicolumn{2}{|c|}{ Total $(n=969)$} & \multicolumn{2}{|c|}{ SGA $(n=475)$} & \multicolumn{2}{|c|}{ Total $(n=969)$} & \multicolumn{2}{|c|}{ SGA $(n=475)$} \\
\hline & $n$ & $\%$ & $n$ & $\%$ & $n$ & $\%$ & $n$ & $\%$ \\
\hline A-Foetus & 569 & 58.7 & 475 & 100.0 & 335 & 34.6 & 241 & 50.7 \\
\hline A1-Lethal congenital anomaly & 142 & 14.7 & 83 & 17.5 & 142 & 14.7 & 83 & 17.5 \\
\hline A2-Infection & 33 & 3.4 & 12 & 2.5 & 33 & 3.4 & 12 & 2.5 \\
\hline A3-Non-immune hydrops & 13 & 1.3 & 3 & 0.6 & 13 & 1.3 & 3 & 0.6 \\
\hline A5-Foetomaternal haemorrhage & 11 & 1.1 & 7 & 1.5 & 11 & 1.1 & 7 & 1.5 \\
\hline A7-Fetal growth restriction & 370 & 38.2 & 370 & 77.9 & 136 & 14.0 & 136 & 28.6 \\
\hline B-Umbilical cord & 65 & 6.7 & & & 116 & 12.0 & 51 & 10.7 \\
\hline B1-Prolapse & 4 & 0.4 & & & 5 & 0.5 & 1 & 0.2 \\
\hline B2-Constricting loop or knot & 54 & 5.6 & & & 97 & 10.0 & 43 & 9.0 \\
\hline B4-Umbilical cord - Other & 7 & 0.7 & & & 14 & 1.4 & 7 & 1.5 \\
\hline C-Placenta & 119 & 12.3 & & & 240 & 24.8 & 121 & 25.5 \\
\hline C1-Placenta abruptio & 68 & 7.0 & & & 103 & 10.6 & 35 & 7.4 \\
\hline C2-Placenta praevia & 1 & 0.1 & & & 2 & 0.2 & 1 & 0.2 \\
\hline C3-Vasa praevia & 4 & 0.4 & & & 5 & 0.5 & 1 & 0.2 \\
\hline C4-Placental insufficiency & 33 & 3.4 & & & 96 & 9.9 & 63 & 13.3 \\
\hline C5-Placenta - Other & 13 & 1.3 & & & 34 & 3.5 & 21 & 4.4 \\
\hline D-Amniotic fluid & 50 & 5.2 & & & 100 & 10.3 & 50 & 10.5 \\
\hline D1-Chorioamnionitis & 36 & 3.7 & & & 55 & 5.7 & 19 & 4.0 \\
\hline D2-Oligohydramnios & 4 & 0.4 & & & 27 & 2.8 & 23 & 4.8 \\
\hline D3-Polyhydramnios & 7 & 0.7 & & & 11 & 1.1 & 4 & 0.8 \\
\hline D4-Amniotic fluid - Other & 3 & 0.3 & & & 7 & 0.7 & 4 & 0.8 \\
\hline E-Uterus & 4 & 0.4 & & & 5 & 0.5 & 1 & 0.2 \\
\hline E2-Anomalies & 4 & 0.4 & & & 5 & 0.5 & 1 & 0.2 \\
\hline F-Mother & 13 & 1.3 & & & 22 & 2.3 & 9 & 1.9 \\
\hline F1-Diabetes & 2 & 0.2 & & & 2 & 0.2 & & \\
\hline F4-Hypertensive diseases in pregnancy & & & & & 1 & 0.1 & 1 & 0.2 \\
\hline F6-Cholestasis & 1 & 0.1 & & & 2 & 0.2 & 1 & 0.2 \\
\hline F7-Drug misuse & & & & & 1 & 0.1 & 1 & 0.2 \\
\hline F8-Maternal - Other & 10 & 1.0 & & & 16 & 1.7 & 6 & 1.3 \\
\hline G-Intrapartum & 12 & 1.2 & & & 14 & 1.4 & 2 & 0.4 \\
\hline G1-Asphyxia & 10 & 1.0 & & & 12 & 1.2 & 2 & 0.4 \\
\hline G2-Birth trauma & 2 & 0.2 & & & 2 & 0.2 & & \\
\hline H-Trauma & 2 & 0.2 & & & 2 & 0.2 & & \\
\hline H1-External trauma & 2 & 0.2 & & & 2 & 0.2 & & \\
\hline I-Unclassified & 135 & 13.9 & & & 135 & 13.9 & & \\
\hline 11-No relevant condition identified & 102 & 10.5 & & & 102 & 10.5 & & \\
\hline I2-No information available & 33 & 3.4 & & & 33 & 3.4 & & \\
\hline
\end{tabular}

† Subcategories with results equal to zero were not mentioned.

categories were umbilical cord (B), placenta (C) and amniotic fluid (D), accounting for $6.7,12.3$, and $5.2 \%$, respectively. Each of the other categories (uterus E, mother F, intrapartum $\mathrm{G}$, trauma $\mathrm{H}$ ) did not exceed $1.3 \%$.
The main changes from RECODE to RECODE-R in the overall sample are also represented in Figure 1. According to the frequencies in the category A subcategories, we distinguished lethal congenital anomalies 
(A1) from "fetus-others" corresponding to A2-A6, and FGR (A7). Inversely, categories $\mathrm{E}-\mathrm{H}$ were combined. From RECODE to RECODE-R, category A decreased substantially from $58.7 \%$ to $34.6 \%$, its largest subcategory being now lethal congenital anomalies (14.7\%) just before FGR (14.0\%). This change increased the numbers of cases in the umbilical cord, placenta and amniotic fluid categories, which nearly doubled to 12.0, 24.8 and 10.3\%, respectively. For the categories assigned to uterus, mother, intrapartum event, and trauma, only a slight increase $(+1.2 \%)$ was observed.

Considering the hierarchical rule of RECODE, all SGA stillbirths were classified in category A, and FGR was retained in $77.9 \%$ (Table 2). The distribution of death conditions was radically different among non-SGA stillbirths: category A accounted for only $19 \%(n=94)$, including $11.9 \%(n=59)$ lethal congenital anomalies, and the main categories $\mathrm{B}-\mathrm{H}$ were more frequently assigned. According to RECODE, unclassified deaths $(n=135,13.9 \%$ of the whole sample) come exclusively from non-SGA stillbirths, and accounted for nearly one-third of them (27.3\%).

Moving FGR down in the RECODE-R hierarchy had no impact on SGA births initially assigned to the subcategories A1-A6 ( $n=105,22.1 \%$ ) (Table 2$)$. By the design of RECODE-R, only stillbirths affected by growth failure and other diseases were redistributed. These 234 cases accounted for $24.1 \%$ of the whole sample and $49.3 \%$ of all SGA stillbirths. Only 136 SGA births (28.6\%) remained classified as FGR. The new related conditions assigned to SGA stillbirths were placental insufficiency (13.3\%), constricting loop or knot (9.0\%) and placenta abruptio (7.4\%).

Table 3 compares the characteristics of reclassified $(n=234)$ and non-reclassified $(n=136)$ stillbirths among the 370 stillbirths initially classified as FGR according to RECODE-R. The changes were independent of gestational age, sex, birth weight ratio, maternal age and time of death. There was a non-significant tendency for

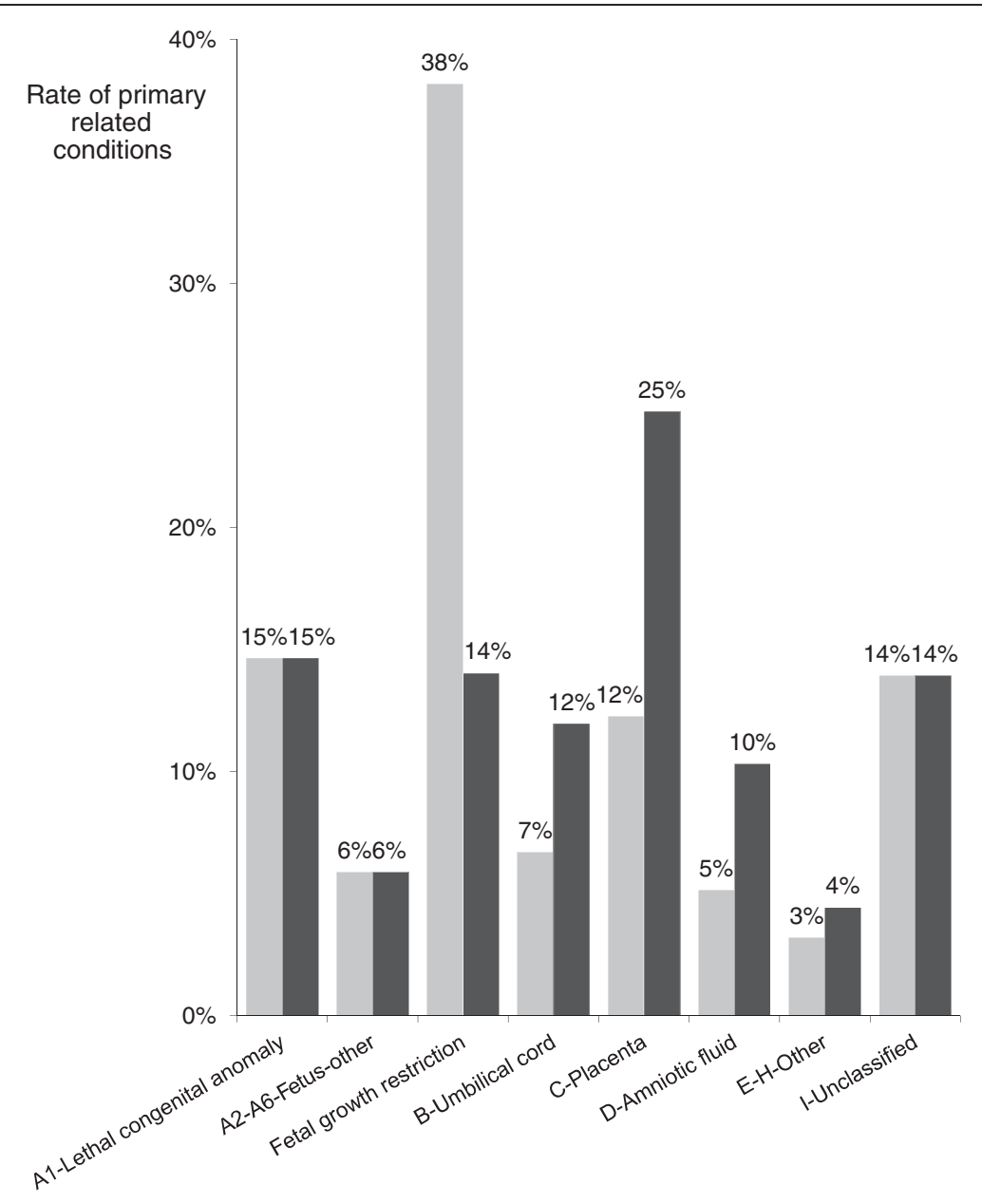

Figure 1 Classification of stillbirths according to RECODE (gray) and RECODE-R (black) ( $n=969$ ). 
Table 3 Characteristics of SGA stillbirths previously classified FGR with RECODE according their reclassification with RECODE-R $(n=370)$

\begin{tabular}{|c|c|c|c|c|c|}
\hline \multirow[t]{3}{*}{$\begin{array}{l}\text { Stillbirth } \\
\text { characteristics }\end{array}$} & \multicolumn{2}{|c|}{ Reclassified $(n=234)$} & \multicolumn{2}{|c|}{$\begin{array}{l}\text { Non-reclassified } \\
(n=136)\end{array}$} & \multirow[t]{3}{*}{ p } \\
\hline & $\mathrm{n}$ & $\%$ & $\mathrm{n}$ & $\%$ & \\
\hline & \multicolumn{2}{|c|}{ mean $\pm s d$} & \multicolumn{2}{|c|}{ mean $\pm s d$} & \\
\hline Maternal age (years) & 30.1 & 5.6 & 29.1 & 5.9 & NS \\
\hline Maternal age (years) & & & & & NS \\
\hline$<25 y$ & 44 & 18.8 & 28 & 20.6 & \\
\hline $25-29 y$ & 65 & 27.8 & 44 & 32.4 & \\
\hline $30-34 y$ & 69 & 29.5 & 44 & 32.4 & \\
\hline$\geq 35 y$ & 56 & 23.9 & 19 & 14.0 & \\
\hline Unknown & & & 1 & 0.7 & \\
\hline $\begin{array}{l}\text { Gestational age } \\
\text { (completed weeks) }\end{array}$ & 30.3 & \pm 6.1 & 29.1 & \pm 5.7 & NS \\
\hline $\begin{array}{l}\text { Gestational age } \\
\text { (completed weeks) }\end{array}$ & & & & & NS \\
\hline $22-28 w$ & 100 & 42.7 & 71 & 52.2 & \\
\hline $29-36 w$ & 79 & 33.9 & 42 & 30.9 & \\
\hline full-term & 55 & 23.5 & 23 & 16.9 & \\
\hline Birth weight (grams) & 1157 & \pm 867 & 1012 & \pm 791 & NS \\
\hline Birth weight percentile & & & & & NS \\
\hline$<3 r d$ & 176 & 75.2 & 112 & 82.4 & \\
\hline 3rd-10th & 58 & 24.8 & 24 & 17.8 & \\
\hline Gender & & & & & NS \\
\hline Male & 123 & 52.6 & 73 & 53.7 & \\
\hline Female & 111 & 47.4 & 63 & 46.3 & \\
\hline Multiple pregnancy & & & & & NS \\
\hline Yes & 27 & 11.5 & 24 & 17.7 & \\
\hline No & 202 & 86.3 & 105 & 77.2 & \\
\hline Unknown & 5 & 2.1 & 7 & 5.1 & \\
\hline Time of death & & & & & NS \\
\hline Intrapartum & 24 & 10.3 & 12 & 8.8 & \\
\hline Antepartum & 203 & 86.8 & 119 & 87.5 & \\
\hline Unknown & 7 & 3.0 & 5 & 3.7 & \\
\hline
\end{tabular}

NS Not Significant $(p>0.05)$.

full-term babies $(p=0.06)$, stillbirths to older women $(p=0.16)$, singletons $(p=0.07)$ and moderate SGA babies $\left(3^{\text {rd }}-10^{\text {th }}\right.$ centile) $(p=0.11)$ to be reclassified.

\section{Discussion}

We tested how the RECODE stillbirth classification performed in a retrospective analysis of a large populationbased database of stillbirths. By moving FGR down in the RECODE hierarchy, so that low birthweight for gestational age was retained only in the absence of other conditions, the proportion of stillbirths assigned to the FGR category decreased from 38.2 to $14.0 \%$. Related conditions of the umbilical cord, placenta and amniotic fluid were highlighted and selected in nearly half of the cases. In particular, with RECODE-R one stillbirth in four is assigned to the category of placental conditions. For SGA babies without congenital malformations or fetal abnormalities, these outcomes seemed to fit the mechanisms of death more closely and illustrate their diversity.

Surveillance of stillbirths in a population is an important epidemiological aim of a registry. There is a need for standardised classifications to improve our understanding of these events and how they evolve. For each death, a number of conditions are often observed that may have contributed to the death and the synthesis and organization of this information presents a challenge. We took the pragmatic point of view adopted by Gardosi et al. and demonstrated the feasibility of a RECODE hierarchical computer-based programme. Froen et al. distinguishes cause of death and associated conditions of death which only "contribute in explaining the circumstances of death in a significant proportion of deaths" [7]. From a clinical point of view, this approach may be frustrating compared to a case-by-case perinatal audit $[7,8,19]$. But this strategy is less time-consuming, retrospectively usable, suitable in an exhaustive and long-standing data collection, and avoids inconsistent identification of cause of death between investigators, countries or study periods. Its main drawback, however, is that it follows a pre-established hierarchy, regardless of whether another condition was evidently a more significant contributor.

The ICD was developed to allow the systematic coding, analysis, interpretation and comparison of morbidity and mortality, and worldwide estimates of stillbirths rate are often provided by these routinely collected data [20]. Recent classifications developed in high-income countries give priority to exhaustive individual analysis, even though some of them ensure compatibility with ICD [7]. The NICE and RECODE classifications are probably unique in using a strictly hierarchical and computerized method applied to ICD codes [21,22]. This approach is consistent with recent recommendations of the authors of The Lancet's Stillbirths series, who advocate a consensus "on a limited number of programmatically relevant, comparable causal categories,... that can be linked to complex classification systems and ICD codes" [23]. This linkage may be improved if mapping could be extended to all ICD codes through a multi-disciplinary action in order to insure consensus on subcategory definitions. Indeed, not all our ICD codes were included in the initial West Midlands algorithm, suggesting that the choice of ICD codes for maternal and fetal conditions may differ by setting. Furthermore, better classifications could be developed if some of the limitations inherent to using ICD codes for the classification of stillbirths are modified in the revision of ICD-11 [3,22]. 
There are a few examples of the RECODE classification system in population-based samples. Our rate of unexplained cases was close to the West Midlands cohort of 2625 stillbirths, the Dutch sample of 485 antepartum singleton stillbirths, or the Italian sample of 154 stillbirths (16.0, 14.2 and 14.3\%, respectively) [5,12,19]. Like Gardosi et al., we reported 15\% lethal congenital anomalies, but our stillbirths classified as FGR (A7) was slightly lower (38.2\% versus $43.0 \%)$. In the two other case series, the authors found only $30.3 \%$ and $16.9 \%$ FGR $[12,19]$. These differences could be due to population selection and most probably to different definitions of SGA births. In particular we were unable to use customized norms which require data on maternal height and weight. This adjustment strengthens the association between SGA and maternal and fetal complications, and the rate of SGA stillbirths was probably slightly underestimated in our study [24].

In our alternative RECODE-R hierarchy of classification, we considered SGA as a common modifier of other underlying maternal and fetal conditions, but not as a specific condition in itself, unless SGA was isolated. In the six classification systems for stillbirth analyzed by Flenady et al., RECODE is the only one with FGR classified as a specific condition [3]. Four of them do not mention FGR, and isolated FGR is put with unexplained cases at the bottom of the list $[6,7,25-27]$. The PSANZ (Perinatal Society of Australia and New Zealand) classification ranks FGR $8^{\text {th }}$ of 11 categories and placental histology defines the subcategories, resulting in a FGR rate of $3.2 \%$ in a recent analysis in New South Wales from 2002 to $2004[6,28]$.

The impact of RECODE-R concerns SGA stillbirths associated with various conditions except fetal conditions. Nevertheless, the main characteristics of reclassified SGA stillbirths did not differ from those of non-reclassified SGA stillbirths. We only found a tendency for full-term, singletons, moderate SGA stillbirths, and stillbirths to mothers aged 35 years or more to be more often reclassified. Several explanations are plausible. Due to specific fetal anomalies, multiple pregnancies are more likely to stay in one of the group A subcategories. The reason that stillbirths to older mothers presented placental, umbilical or maternal conditions more often, and consequently were reclassified more often, may be related to a higher frequency of maternal complications with advanced maternal age. The mechanisms for full-term stillbirths is less clear especially as late stillbirths are those that are more likely to remain unexplained $[29,30]$. On the other hand, post-mortem investigations could be performed more often for full-term stillbirths, so that this information is highlighted. The mild severity of growth failure among full-term versus preterm stillbirths had already been described [31]. Finally the fact that severe compared to moderate SGA stillbirths stay preferentially in the FGR category might be a reasonable argument for using RECODE-R. The impact of RECODE-R on the classification of SGA stillbirths according to their characteristics, and the hypothesized mechanisms should be confirmed in larger studies.

\section{Conclusions}

Monitoring stillbirth rates and capturing the reality of primary clinical conditions associated with fetal death remains an ambitious challenge. Using a hierarchical system within a classification requires defining priorities among the circumstances of death; this strategy is a complementary approach to the perinatal audit designed to identify cause of death. RECODE underlines the frequency of growth failure among stillbirths and the importance of improving prenatal detection of FGR. In contrast, RECODE-R may be closer to etiological mechanisms leading to death and supports the use of postmortem investigations. Given that the selection of a classification leads to important differences in the clinical conditions which are underscored; these choices should be made explicit and justified with respect to the objective of the analyses.

\section{Abbreviations}

SGA: Small for gestational age; FGR: Fetal growth restriction.

\section{Competing interests}

The authors declare that they have no competing interests.

\section{Authors' contributions}

$A E$ and $J Z$ have been involved in conception and design, analysis and interpretation of data, and draft of the manuscript. PB has been involved in analysing the data and drafting the manuscript. CC, PSJ and TD revised it for important intellectual content and gave final approval of the version to be published. SC, AF and MBM contributed to acquisition of data. All authors read and approved the final manuscript.

\section{Acknowledgements}

This work was supported by the Institut National de la Santé et de la Recherche Médicale (INSERM), the Institut National de Veille Sanitaire (INVS), and the Conseils Généraux of the districts of Isère, Savoie and Haute-Savoie. We particularly appreciated the experience and the help of Prof. Jason Gardosi for encoding the different RECODE conditions. We are also grateful to all the RHEOP members, especially Claire Ambrico, Magalie Piret and Catherine Tronc, for their contribution in data collection, completeness and quality control.

\section{Author details}

${ }^{1}$ The RHEOP (Registre des Handicaps de I'Enfant et Observatoire Périnatal Isère, Savoie et Haute-Savoie), Grenoble, France. ${ }^{2}$ INSERM, UMR S953, Epidemiological Research on Perinatal Health and Women's and Children's Health, Paris, France. ${ }^{3}$ The THEMAS, UJF-Grenoble 1, Grenoble, France. ${ }^{4}$ DMIS, Pavillon Taillefer, CHU Grenoble, CS 10217, 38043 Grenoble Cedex 9, France.

Received: 15 May 2013 Accepted: 26 September 2013

Published: 3 October 2013

\section{References}

1. Gordijn SJ, Korteweg FJ, Erwich JJ, Holm JP, van Diem MT, Bergman KA, Timmer A: A multilayered approach for the analysis of perinatal mortality using different classification systems. Eur J Obstet Gynecol Reprod Biol 2009, 144(2):99-104. 
2. Reddy UM, Goldenberg R, Silver R, Smith GC, Pauli RM, Wapner RJ, Gardosi J, Pinar H, Grafe M, Kupferminc M, et al: Stillbirth classificationdeveloping an international consensus for research: executive summary of a National Institute of Child Health and Human Development workshop. Obstet Gynecol 2009, 114(4):901-914.

3. Flenady V, Froen JF, Pinar H, Torabi R, Saastad E, Guyon G, Russell L, Charles A, Harrison C, Chauke L, et al: An evaluation of classification systems for stillbirth. BMC Pregnancy Childbirth 2009, 9:24.

4. Flenady V, Middleton P, Smith GC, Duke W, Erwich JJ, Khong TY, Neilson J, Ezzati M, Koopmans L, Ellwood D, et al: Stillbirths: the way forward in high-income countries. Lancet 2011, 377(9778):1703-1717.

5. Gardosi J, Kady SM, McGeown P, Francis A, Tonks A: Classification of stillbirth by relevant condition at death (ReCoDe): population based cohort study. BMJ 2005, 331(7525):1113-1117.

6. Chan A, King JF, Flenady V, Haslam RH, Tudehope Dl: Classification of perinatal deaths: development of the Australian and New Zealand classifications. J Paediatr Child Health 2004, 40(7):340-347.

7. Froen JF, Pinar H, Flenady V, Bahrin S, Charles A, Chauke L, Day K, Duke CW, Facchinetti F, Fretts RC, et al: Causes of death and associated conditions (Codac): a utilitarian approach to the classification of perinatal deaths. BMC Pregnancy Childbirth 2009, 9:22.

8. Dudley DJ, Goldenberg R, Conway D, Silver RM, Saade GR, Varner MW, Pinar H, Coustan D, Bukowski R, Stoll B, et al: A new system for determining the causes of stillbirth. Obstet Gynecol 2010, 116(2):254-260.

9. Gardosi J, Madurasinghe V, Williams M, Malik A, Francis A: Maternal and fetal risk factors for stillbirth: population based study. BMJ 2013, 346:f108.

10. Froen JF, Gardosi JO, Thurmann A, Francis A, Stray-Pedersen B: Restricted fetal growth in sudden intrauterine unexplained death. Acta Obstet Gynecol Scand 2004, 83(9):801-807.

11. Kidron D, Bernheim J, Aviram R: Placental findings contributing to fetal death, a study of 120 stillbirths between 23 and 40 weeks gestation. Placenta 2009, 30(8):700-704.

12. Korteweg FJ, Gordijn SJ, Timmer A, Holm JP, Ravise JM, Erwich JJ: A placental cause of intra-uterine fetal death depends on the perinatal mortality classification system used. Placenta 2008, 29(1):71-80.

13. Rey $S$, Hoffmann P, Arnould P, Jouk PS, Tronc C, Cans C: Tendances et caractéristiques de la mortinatalité dans trois départements alpins (I'Isère, la Savoie et la Haute-Savoie). Revue de médecine périnatale 2009, 1(4):200-207.

14. WHO: International statistical classification of diseases and related health problems. Tenth Revision. 2nd edition. Geneva, Switzerland: World Health Organization; 1993:129.

15. Gardosi J, Mongelli M, Wilcox $M$, Chang A: An adjustable fetal weight standard. Ultrasound Obstet Gynecol 1995, 6(3):168-174.

16. Ego A, Subtil D, Grange G, Thiebaugeorges O, Senat MV, Vayssiere C, Zeitlin J: Customized versus population-based birth weight standards for identifying growth restricted infants: a French multicenter study. Am J Obstet Gynecol 2006, 194(4):1042-1049.

17. Blondel B, Norton J, du Mazaubrun C, Breart G: Development of the main indicators of perinatal health in metropolitan France between 1995 and 1998. Results of the national perinatal survey. Journal de gynecologie, obstetrique et biologie de la reproduction 2001, 30(6):552-564.

18. Hadlock FP, Harrist RB, Martinez-Poyer J: In utero analysis of fetal growth: a sonographic weight standard. Radiology 1991, 181(1):129-133.

19. Vergani P, Cozzolino S, Pozzi E, Cuttin MS, Greco M, Ornaghi S, Lucchini V: Identifying the causes of stillbirth: a comparison of four classification systems. Am J Obstet Gynecol 2008, 199(3):e311-314.

20. Cousens S, Blencowe H, Stanton C, Chou D, Ahmed S, Steinhardt L, Creanga AA, Tuncalp O, Balsara ZP, Gupta S, et al: National, regional, and worldwide estimates of stillbirth rates in 2009 with trends since 1995: a systematic analysis. Lancet 2011, 377(9774):1319-1330.

21. Winbo IG, Serenius FH, Dahlquist GG, Kallen BA: NICE, a new cause of death classification for stillbirths and neonatal deaths. Neonatal and Intrauterine Death Classification according to Etiology. Int J Epidemiol 1998, 27(3):499-504.

22. Froen JF, Gordijn SJ, Abdel-Aleem H, Bergsjo P, Betran A, Duke CW, Fauveau V, Flenady V, Hinderaker SG, Hofmeyr GJ, et al: Making stillbirths count, making numbers talk - issues in data collection for stillbirths. BMC Pregnancy Childbirth 2009, 9:58.

23. Lawn JE, Blencowe H, Pattinson R, Cousens S, Kumar R, Ibiebele I, Gardosi J, Day LT, Stanton C: S: Where? When? Why? How to make the data count? Lancet 2011, 377(9775):1448-1463.
24. Gardosi J, Figueras F, Clausson B, Francis A: The customised growth potential: an international research tool to study the epidemiology of fetal growth. Paediatr Perinat Epidemiol 2011, 25(1):2-10.

25. Cole SK, Hey EN, Thomson AM: Classifying perinatal death: an obstetric approach. Br J Obstet Gynaecol 1986, 93(12):1204-1212.

26. Korteweg FJ, Gordijn SJ, Timmer A, Erwich JJ, Bergman KA, Bouman K Ravise JM, Heringa MP, Holm JP: The Tulip classification of perinatal mortality: introduction and multidisciplinary inter-rater agreement. Bjog 2006, 113(4):393-401.

27. Wigglesworth JS: Monitoring perinatal mortality. A pathophysiological approach. Lancet 1980, 2(8196):684-686.

28. Gordon A, Jeffery HE: Classification and description of stillbirths in New South Wales, 2002-2004. Med J Aust 2008, 188(11):645-648.

29. Froen JF, Arnestad M, Frey K, Vege A, Saugstad OD, Stray-Pedersen B: Risk factors for sudden intrauterine unexplained death: epidemiologic characteristics of singleton cases in Oslo, Norway, 1986-1995. Am J Obstet Gynecol 2001, 184(4):694-702.

30. Huang DY, Usher RH, Kramer MS, Yang H, Morin L, Fretts RC: Determinants of unexplained antepartum fetal deaths. Obstet Gynecol 2000, 95(2):215-221.

31. Gardosi J: Systematic reviews: insufficient evidence on which to base medicine. Br J Obstet Gynaecol 1998, 105(1):1-5.

doi:10.1186/1471-2393-13-182

Cite this article as: Ego et al:: Stillbirth classification in population-based data and role of fetal growth restriction: the example of RECODE. BMC Pregnancy and Childbirth 2013 13:170.

\section{Submit your next manuscript to BioMed Central and take full advantage of:}

- Convenient online submission

- Thorough peer review

- No space constraints or color figure charges

- Immediate publication on acceptance

- Inclusion in PubMed, CAS, Scopus and Google Scholar

- Research which is freely available for redistribution 